\title{
Title: Fundamental basis of single-point liquid limit measurement approaches
}

\section{$\underline{\text { Technical Paper }}$}

Submitted to Applied Clay Science

Dr S. K. Haigh, MEng MA PhD Cantab.

University Senior Lecturer in Geotechnical Engineering

Department of Engineering

University of Cambridge

United Kingdom

skh20@cam.ac.uk

Dr P. J. Vardanega, BE MEngSc Qld.UT PhD Cantab., MIEAust M.ASCE

Lecturer in Civil Engineering

Department of Civil Engineering

Faculty of Engineering

University of Bristol

United Kingdom

p.j.vardanega@bristol.ac.uk

No. of words

Date version drafted:

$9^{\text {th }}$ October 2014 


\section{NOTATION}

Roman

a curve fitting parameter

$b \quad$ curve fitting parameter

$c_{u} \quad$ undrained shear strength

$c_{u} / \rho \quad$ specific soil strength

$\left(c_{u} / \rho\right)_{\mathrm{LL}} \quad$ specific soil strength at liquid limit

FI flow index

$G_{s} \quad$ specific gravity

$I_{L} \quad$ liquidity index

$I_{P} \quad$ plasticity index

$n \quad$ curve fitting parameter

$N \quad$ number of blows during the Casagrande Liquid Limit Test

$P I_{\text {cone }} \quad$ plasticity index determined using the fall cone liquid limit and the thread rolling test

w water content

$w_{L} \quad$ liquid limit (Casagrande)

$w_{L_{-} c o n e} \quad$ liquid limit (Fall Cone)

Greek

$\alpha \quad$ fitting parameter

$\tan \beta \quad$ slope of the flow line

$\rho \quad$ density of soil

$\rho_{w} \quad$ density of water

Statistical terms

$R^{2} \quad$ coefficient of determination

$n \quad$ number of data points used to generate a regression

SE standard error of a regression 


\section{INTRODUCTION}

2 The consistency limits first defined by Atterberg (1911a and 1911b) describe the behaviour

3 of clays with varying water content, and as such play a vital role in the use of clays in both

4 geotechnical and industrial applications (e.g. Andrade et al. 2011). The plastic limit of clays is

5 the water content at which the transition from ductile to brittle behaviour suddenly occurs, as

6 discussed by Haigh et al. (2013), Haigh et al. (2014) and Barnes (2013). The liquid limit is

7 defined as the water content when a clay's behaviour changes from liquid to plastic this

8 transitions is gradual rather than sudden. The definition of the transition boundary is thus

9 inherently arbitrary. Warkentin (1961) postulated that the liquid limit (tested using the

10 Casagrande apparatus) was controlled by interparticle forces - this thesis was further

11 examined by Nagaraj and Jayadeva (1981) who suggested that liquid limit was associated

12 with a certain spacing between clay platelets and thus with surface areas of particles.

13 A clay's liquid limit can be determined using either fall-cone or percussion methods. The 14 percussion cup method of determining the liquid limit has its origins in the work of Atterberg 15 (1911a, 1911b) and was standardised by Casagrande (1932). The standard test involves manipulating the water-content of a soil specimen such that 25 blows are required for closure

17 of a standard groove over a length of $13 \mathrm{~mm}$. As it is difficult to achieve groove-closure at exactly 25 blows, data from several tests are plotted on axes of water content versus the 19 logarithm of the number of blows and a straight-line, termed the flow-line, is fitted to the 20 data. The liquid limit is taken to be the water-content at which this line crosses 25 blows.

21 The fall-cone test for liquid limit involves manipulating the water-content of a clay 22 specimen such that an $80 \mathrm{~g}, 30^{\circ}$ cone placed with its tip on the surface of the clay will fall 20 $\mathrm{mm}$ before coming to rest - this test can also be used to estimate undrained shear strength of clays (e.g. Hansbo, 1957 and Yukselen-Aksoy, 2010). In this procedure data from several 
tests is typically plotted on axes of water content versus the logarithm of penetration and a straight line is fitted to the data.

27 In order to improve the speed at which these tests can be carried out, single point methods have been proposed for both percussive (Waterways Experiment Station, 1949) and fall-cone tests (Clayton and Jukes 1978) to allow the liquid limit to be inferred from a test in which the clay sample was not at the liquid limit water content.

31 This paper will demonstrate that these single-point methods, while originally determined empirically, can be derived from fundamental mechanical principles. Further it will be shown that the variations in these methods prescribed by international design codes relate to differences in the equipment in use worldwide, rather than to differences between the soils tested.

\section{DEVELOPMENT OF SINGLE POINT LIQUID LIMIT PROCEDURES}

The single point method for percussive liquid limit was first proposed by the US Army

$47 \log \left(\frac{w}{w_{L}}\right)=-\tan \beta \log \left(\frac{N}{25}\right)$

$49 \quad w_{L}=w\left(\frac{N}{25}\right)^{\tan \beta}$ 
50 The average value of $\tan \beta$ for the soils tested was found to be 0.121 , (Waterways

51 Experiment Station, 1949). This relationship subsequently became the single-point liquid

52 limit method implemented as 'Method B' in ASTM D4318 (2010). Equation (2) was also

53 reported to be an acceptable match for 676 soils from the Buenos Aires region of Argentina

54 (Trevisán, 1960). Table 1 shows various reported values of $\tan \beta$ based on seven databases of 55 liquid limit tests for which this analysis has been reported.

56 These geographically diverse observations confirm the general trend of flow lines having 57 slopes of approximately 0.1 with a standard deviation of the order of 0.03 , but do show 58 substantial differences in different regions. This has since resulted in ASTM D4318 (2010) 59 using a value of $\tan \beta$ of 0.121 following Waterways Experiment Station (1949), BS 1377601990 using a value of 0.092 following Norman (1959) and AS1289 (2009) using a value of 61 0.091. The Indian standard IS2720 (1985) uses a slightly different formula that was proposed 62 by Nagaraj and Jayadeva (1981):

$63 \quad w_{L}=\frac{w}{1.3215-0.23 \log (N)}$

64 The effect of these different corrections on the liquid limit measured can be seen in Figure 65 1. It can be seen that while the lines differ marginally in shape, there is little significant 66 difference between the formulae suggested by BS1377-1990 and IS2720-1985. The IS2720-

671985 formula can be shown to be functionally equivalent to the use of a value of $\tan \beta$ of $68 \quad 0.101$.

69 There are two plausible explanations for the difference in value of $\tan \beta$ between the United

70 States and the United Kingdom (or in a comparison of data from any other two countries); 71 differences in soils or differences in testing equipment (the type of Casagrande device used). 72 If the single-point method is to be used in countries whose soils have not been so thoroughly 73 analysed, the influence of these two aspects is important in determining an appropriate value 74 of $\tan \beta$. 
75 This paper draws on recently published work on both the mechanics of the Casagrande 76 liquid limit test (Haigh, 2012) and the variation of soil strength between the liquid and plastic 77 limits (O'Kelly, 2013 and Vardanega and Haigh, 2014) to demonstrate the origins of the 78 relationships used in the single-point liquid limit method and to show that it is the 79 characteristics of the equipment used that should determine which value of $\tan \beta$ is 80 appropriate, rather than the origin of the soil samples. The single point method remains a 81 viable method for liquid limit determination, permitted in many codes of practice worldwide, 82 and is therefore worthy of further examination.

\section{ANALYSIS}

85 Haigh (2012) carried out a Newmarkian sliding block analysis (Newmark, 1965) of the 86 percussion cup test, using the vertical acceleration pulse measured on the cup during its 87 impact with the base of the liquid limit device to drive a slope-failure within the soil. He demonstrated that the liquid limit of soil, as measured with ASTM standard percussion cup apparatus, corresponds to a ratio of undrained shear strength to soil density of approximately

$901 \mathrm{~m}^{2} \mathrm{~s}^{-2}$. Haigh (2012) also demonstrated, by utilisation of this analysis, the dependence of the 91 number of blows required to cause groove closure on the specific strength of the soil, as 92 shown in Figure 2.

93 In order to use this analytically calculated curve in the analysis presented here, a power-law 94 relationship of the form:

$95 \quad N=a+b\left(\frac{c_{u}}{\rho}\right)^{n}$

96 is fitted to the specific strength curve between 10 and 35 blows, as shown in Figure 2. Giving

97 the experimental curve for an ASTM device (Haigh, 2012):

$98 \quad N=6.22+21.43\left(\frac{c_{u}}{\rho}\right)^{1.893}$ 
121

Casagrande (1958) recognised the variability between different liquid limit devices and made efforts to further standardise construction of the devices. Two categories of device still exist, however, those with hard plastic bases as specified by ASTM D4318 (2010), and those with softer rubber bases as specified by BS1377 (1990), IS9259 (1979) and AS1289 (2009). The reasons for this distinction appear to be historical rather than based on any scientific decision.

The base characteristics prescribed by the aforementioned codes are shown in Table 1. The hardness of the base alters the characteristics of the shock loading on the clay slopes during the liquid limit test and hence the movement of the soil that will occur during one blow for any given soil specific strength. By measuring the vertical acceleration measured on impact with the base and following the analysis procedure outlined by Haigh (2012), the relationship between number of blows for groove closure and specific strength can be derived for each particular Casagrande apparatus. Table 2 shows the best-fit parameters for new apparatus manufactured by ELE International conforming to the ASTM and British Standards and for Indian Standard apparatus tested at the Indian Institute of Science (Bangalore) - the parameters derived for the three devices tested differ considerably.

The single-point liquid limit method (defined by equation 2) implies that a unique relationship exists between the water content of a soil normalised by that at its liquid limit and the number of blows required to cause the groove to close in the liquid limit test. Following Haigh (2012), this implies relationships between the normalised water content and both the strength and density of the soil.

The relationship between the water content of the soil and its density in a saturated state can be found from:

$\rho=\frac{G_{s}(1+w)}{1+w G_{s}} \rho_{w}$

As specific gravity is reasonably constant for the majority of soils at around $2.65 \pm 0.2$, the relationship between water content and density is also approximately identical for all soils. 
124 The variation of undrained strength with water content has been estimated using a variety of 125 relationships, usually assuming either a linear relationship between the logarithm of undrained 126 strength and liquidity index, (e.g. Wroth and Wood, 1978) or a power law relationship 127 between undrained strength and liquidity index (e.g. Feng, 2001, Y1lmaz, 2009 and Zentar et 128 al. 2009).

129 Vardanega and Haigh (2014) have shown through the analysis of a large database collected 130 fall-cone data on a diverse database of over 100 soils that a log-linear relationship between 131 strength and liquidity index provides an acceptable match to the data for liquidity indices 132 between 0.2 and 1.1 (in the same paper a power law is shown to be also a plausible fit to the 133 dataset and the following analysis could be repeated assuming such a relation that would 134 make use of the logarithmic liquidity index proposed by Koumoto and Houlsby, 2001 and 135 used in Vardanega and Haigh, 2014). The slope of the relationship is, however, shown to be 136 significantly less than that suggested by (Wroth and Wood, 1978); the strength variation with 137 water content being shown to be approximated by:

$\left.138 \quad c_{u}=1700 \times 35^{\left[\left[\frac{w_{L} \text { cone } e^{-w}}{P I_{\text {cone }}}\right]\right.}\right] \quad c_{u}$ in $\mathrm{Pa} \quad 0.2<I_{L}<1.1$

139 Similar values for the variation of strength with water content around liquid limit can be 140 derived from the fall-cone single-point liquid limit procedure outlined by Clayton and Jukes 141 (1978).

142 As previously mentioned, the variation of the number of blows to cause the groove to close 143 in the liquid limit test with water content is often characterised by the slope of the flow line $144 \tan \beta$. The relationship between this slope and the variations of both the soil specific strength 145 with water content and the number of blows for groove closure with specific strength can be 146 determined by multiplication of the derivatives, as shown in equation 8.

$147 \tan \beta=-\frac{\partial \log _{10} w}{\partial \log _{10} N}=-\frac{\partial \log _{10} w}{\partial \mathrm{w}} \frac{\partial \mathrm{N}}{\partial \log _{10} N} \frac{\partial \mathrm{w}}{\partial \frac{\mathrm{c} u}{\rho}} \frac{\partial \frac{\mathrm{c} u}{\rho}}{\partial \mathrm{N}}$ 
148 The derivatives required by equation 8 can be calculated by differentiating equations 6 and 7

149 to yield:

$150 \quad \frac{\partial \frac{\mathrm{c} u}{\rho}}{\partial w}=\frac{\rho \frac{\partial \mathrm{c}_{u}}{\partial w}-\mathrm{c}_{u} \frac{\partial \rho}{\partial w}}{\rho^{2}}=-\frac{\mathrm{c}_{u}}{\rho}\left[\frac{\ln (35)}{P I_{\text {cone }}}+\frac{1-G_{S}}{\left(1+w G_{S}\right)(1+w)}\right]$

151 And by differentiating equation 4 to yield:

$152 \quad \frac{\partial \mathrm{N}}{\partial \frac{\mathrm{c}_{u}}{\rho}}=b n\left(\frac{\mathrm{c}_{u}}{\rho}\right)^{n-1}$

153 Evaluating $\tan \beta$ at Casagrande's liquid limit $w_{L}$ thus yields:

154

$\tan \beta=\frac{25}{(25-a) n w_{L}\left[\frac{\ln (35)}{P I_{\text {cone }}}+\frac{\left(1-G_{S}\right)}{\left(1+w_{L} G_{S}\right)\left(1+w_{L}\right)}\right]}$

155 The first additive term in the denominator will always dominate, hence:

$156 \tan \beta \approx \frac{25}{b n\left(\frac{c_{u}}{\rho}\right)_{L L}^{n} \ln (35)} \frac{P I_{\text {cone }}}{w_{L}}=\zeta \frac{P I_{\text {cone }}}{w_{L}}$

157 Substituting in the values from table 2:

158

$\tan \beta_{A S T M} \approx 0.198 \frac{P I_{\text {cone }}}{w_{L}} \quad \tan \beta_{B S} \approx 0.161 \frac{P I_{\text {cone }}}{w_{L}} \quad \tan \beta_{I S} \approx 0.102 \frac{P I_{\text {cone }}}{w_{L}}$

159 Equation 13 is inconsistent, in that it combines the plasticity index found using the cone

160 method for liquid limit determination with the liquid limit water content for the Casagrande

161 cup method. In order to remove this inconsistency and to eliminate the need for the 162 simplification of equation 11 to equation 12 , $\tan \beta$ was evaluated numerically for plastic 163 limits between $10 \%$ and $100 \%$ and cone plasticity indices between $10 \%$ and $300 \%$. For each 164 combination of parameters, the strength variation around liquid limit was assumed to be given 165 by equation 7 and the density variation by equation 6 . The number of blows to failure for a 166 variety of water contents could then be determined based on equation 4 with appropriate 167 parameters from table 1, and the flow index, Casagrande liquid limit and plasticity index 168 could then be determined. Equation 12 can thus be modified to be consistent in only using 169 Casagrande values of plasticity index and liquid limit to yield: 
$170 \tan \beta=\alpha \frac{P I}{w_{L}}$

171 Figure 3 shows the calculated values of $\alpha$ (as defined by equation 14) for different

172 Casagrande-style equipment. It can be seen that $\alpha$ is equal to $0.22 \pm 0.02$ for ASTM 173 equipment, $0.14 \pm 0.01$ for British Standards equipment and $0.09 \pm 0.01$ for Indian Standard

174 equipment. These numbers compare favourably with the values given in equation 13 . As $\alpha$ is

175 a function of plasticity index as well as liquid limit, the relationship between $\alpha$ and liquid

176 limit was evaluated for soils lying on both the Casagrande A-Line (equation 15) and the U-

177 Line (ASTM, 2006) (equation 16), considered the upper limit of the relation developed by

178 Casagrande (1947). The origin of the U-line defined by equation 16 is discussed by Howard

179 (1984). The resultant lines (on Figure 3) are essentially coincident. Plasticity index therefore

180 has only a minor influence on the results for a sensible range of $I_{p}$ values.

$181 \quad I_{P}=0.73\left(w_{L}-0.20\right)$

$182 \quad I_{P}=0.90\left(w_{L}-0.08\right)$

183 Equation 14 with ASTM parameters was applied to the soils in the database of Vardanega 184 and Haigh (2014) resulting in a prediction of $\tan \beta$ having an average value of 0.127 and a 185 standard deviation of 0.026. This value is similar to the results from Eden (1959) and the 186 Waterways Experimental Station (1949). Using the parameters found for British Standard 187 equipment, a prediction of $\tan \beta$ having an average value of 0.081 and a standard deviation of 1880.021 results. This is similar to the reported observations of Mohan and Goel (1958), Norman 189 (1959) and Jain and Patwardhan (1960)._These values are calculated assuming a constant 190 value of $G_{s}$ for all soils of 2.65. The analysis can be shown to be insensitive to specific 191 gravity, $\tan \beta$ only changing by 0.002 if the extremes of plausible values of $G_{s}$ for clays are 192 used.

193 It can be seen from equation 12 that a relationship exists between the slope of the flow line 194 and the ratio between plasticity index and liquid limit. The plastic limit could hence 
195 conceivably be estimated from the measured liquid limit data by extrapolation. Sridharan et

196 al. (1999) defined the slope of results from a Casagrande liquid limit test using a flow index

197 FI defined by:

$198 \quad F I=-\frac{\partial \mathrm{w}}{\partial \log _{10} N}$

199 They then showed that a regression to a dataset gave a good correlation $\left(R^{2}=0.88, n=55\right.$,

$200 S E=1.8 \%$ ) between flow index and plasticity index of the form:

$201 P I=4.12 F I$

202 Data from Jain and Patwardhan (1960) can also be analysed within this framework to give a 203 relationship between flow and plasticity indices with all test carried out by the same 204 laboratory. This gives a substantially different but still significant $\left(R^{2}=0.52, n=32, S E=0.69 \%\right)$ 205 correlation:

$206 P I=1.96 F I$

207 The substantial difference between equations 18 and 19 calls into question the validity of any 208 unique correlation between plasticity index and flow index, despite each of the correlations 209 being significant for the data used to derive it. Soil characteristics are unlikely to be the key 210 source of variability, rather it appears that the precise characteristics of the equipment used to 211 carry out the testing have a large impact on the ratio of plasticity and flow indices.

212 It can be seen from Figure 4 that for each of the three sets of equipment tested, the ratio of 213 plasticity index to flow index is approximately constant for liquid limits between $20 \%$ and $214400 \%$, but that there are large differences between the three devices; ASTM equipment giving 215 a ratio of approximately 2, British Standard equipment 3.1 and Indian Standard equipment 216 4.7. This latter value approximates the value of 4.12 given in equation 18 and derived by 217 Sridharan et al. (1999) using the precise Indian Standard equipment tested for this research. 218 As described earlier, Jain and Patwardhan (1960) observed a different correlation between 219 plasticity and flow indices, but the ratio observed in their data (1.96) also falls within the 
range that would be predicted for the three sets of equipment tested here, being consistent with the use of ASTM equipment.

The plasticity and flow indices for the 55 soils for which Casagrande liquid limits were presented by Sridharan et al. (1999) are shown in Figure 5 together with the predicted relationships using the three Casagrande cups tested here. Using the derived parameters for the equipment used to measure the plasticity and flow indices, (i.e. that at IISc Bangalore), a good prediction of the data can be obtained, though there is significant scatter about the trend. Predictions of the value of flow index based on liquid limit were also made as part of a singlepoint liquid limit procedure developed by Fang (1960). The method involved predicting the slope of the flow line for a given soil and then extrapolating this flow line to the water content at 25 blows to give the liquid limit. In order to predict the slope of the flow-line, Fang correlated data on 469 soil tests carried out during the AASHO (American Association of State Highway Officials) road test (Burggraf and McKendrick, 1956) and by the Washington State Highway Department to predict that the flow index could be approximated by:

$F I=0.36\left(w_{L}-0.08\right)$

Utilising the analysis presented here, (assuming ASTM apparatus) this can be compared to the predicted values of flow index for soils falling on the A and U lines, as shown in Figure 6. It can be seen that the average values of flow index measured by Fang fall in exactly the region expected, being appropriate for soils lying above the A-line and below the U-line. The power law expressions of the single-point liquid limit test (equation 2) can also be presented on this figure. ASTM method $\mathrm{B}$, using a value of $\tan \beta$ of 0.121 can be shown to give:

$$
F I=\tan \beta \ln (10) w_{L}=0.279 w_{L}
$$

This is broadly consistent with the analysis presented here, being applicable for soils lying close to the A-line for soils having liquid limits between 20 and $120 \%$. 
245

246 The following summary points can be made:

247 (a) The liquid limit of soils as measured by the Casagrande apparatus was shown by Haigh 248

\section{SUMMARY}

(2012) to be an assessment of specific strength. Utilising this analysis along with trends of changing soil strength with water content $\left(I_{L}\right)$, as outlined by Vardanega and Haigh (2014) allows an understanding of the mechanics underpinning the single-point liquid limit tests proposed by several authors and implemented as part of ASTM D4318-10 and BS1377-1990 amongst other design codes.

(b) The difference between the implementation of the single point liquid limit method by the two codes (ASTM and BS1377) has been shown to be predominantly a function of the differences in equipment specified (i.e. hard or soft base Casagrande devices) rather than being due to the nature of the soils in the two countries. It is suggested that those countries utilising hard-based Casagrande equipment (e.g. USA) should use a value of $\tan \beta$ of 0.121 , and those using soft-base equipment (e.g. UK, India \& Australia) a value of 0.092, regardless of the origin of the soils being tested.

(c) While the relationship between the plasticity index and flow index, as previously described by Sridharan et al. (1999), has a fundamental basis in the mechanics of the test, potentially allowing a liquid limit test to be used to estimate the plastic limit of a soil, this would however have substantial uncertainties, both due to the scatter seen in the data for a single set of equipment and due to the variable nature of liquid limit test devices in operation worldwide. 


\section{ACKNOWLEDGEMENTS}

271 The authors would like to thank Professor S. P.G Madabhushi and Professor A. Sridharan

272 for their assistance in acquiring data from the liquid limit apparatus at Indian Institute of 273 Science, Bangalore.

274

275 REFERENCES

276 Andrade, F. A., Al-Qureshi, H. A. and Hotza, D. (2011). Measuring the plasticity of clays: A 277 Review. Applied Clay Science, 51: 1-7.

278 ASTM (2010). Standard test methods for liquid limit, plastic limit, and plasticity index of 279 soils. ASTM International, ASTM D4318-10

280 ASTM (2006). Standard Provision for Classification of Soils for Engineering Purposes 281 (Unified Soil Classification System). ASTM International, ASTM D2487-06.

282 Atterberg, A. (1911a). Lerornas forhållande till vatten, deras plasticitetsgränser och 283 plasticitetsgrader. Kungliga Lantbruksakademiens Handlingar och Tidskrift, 50(2): 132284 158. (In Swedish)

285 Atterberg, A. (1911b). Die Plastizität der Tone. Internationale Mitteilungen der Bodenkunde, 286 1: 4-37 (In German).

Australian Standard AS1289 (2009). Methods of testing soils for engineering purposes, $288 \quad$ Standards Australia, Sydney.

Barnes, G. E. (2013). An apparatus for the determination of the workability and plastic limit of clays. Applied Clay Science, 80-81: 281-290

British Standard BS1377 (1990). Methods of Test for Soils for Civil Engineering Purposes, British Standards Institution, London.

Burggraf F. and McKendrick W. B. (1956). Large-scale highway research - AASHO road 294 test. Civil Engineering, 60(12): 799-804. 
295 Casagrande, A. (1932). Research on the Atterberg Limits of Soils. Public Roads, 13(8): 121296136.

297 Casagrande, A. (1947). Classification and identification of soils. Proceedings of the American 298 Society of Civil Engineers, 73(6): 783-810.

299 Casagrande A (1958). Notes on the design of the liquid limit device. Géotechnique 8(2): 8430091.

301 Clayton, C. R. and Jukes, A. W. (1978). A one point cone penetrometer liquid limit test? 302 Géotechnique, 28(4): 469-472.

303 Eden, W. J. (1955). Trial of one-point liquid limit method. Proceedings of Ninth Canadian 304 Soil Mechanics Conference. Ottawa, December $15^{\text {th }}$ to $16^{\text {th }} 1955$ (National Research 305 Council for Canada), Appendix A.

306 Eden, W. J. (1959). Use of a one-point liquid limit procedure. ASTM Special Technical 307 Publication, 254: 168-176

308 Fang, H. Y. (1960). Rapid determination of liquid limit of soils by flow index method. $309 \quad$ Highway Research Board Bulletin, 254: 30-35

310 Feng, T. (2001). A linear $\log d-\log w$ model for the determination of consistency limits of $311 \quad$ soils. Canadian Geotechnical Journal, 38(6): 1335-1342.

312 Haigh, S. K. (2012). Mechanics of the Casagrande liquid limit test. Canadian Geotechnical $313 \quad$ Journal, 49 (9): 1015-1023. Corrigenda, 49 (9): 1116 and 49 (11): 1329.

314 Haigh, S. K., Vardanega, P. J., and Bolton, M. D. (2013). The plastic limit of clays. 315 Géotechnique, 63(6): 435-440.

316 Haigh, S. K., Vardanega, P. J., Bolton, M. D. \& Barnes, G. E. (2014). Discussion of "The 317 plastic limit of clays". Géotechnique, 64(7): 584-586.

318 Hansbo, S. (1957). A new approach to the determination of the shear strength of clay by the 319 fall cone test. Swedish Geotechnical Institute Proceedings, 14: 5-47. 
320 Howard, A. K. (1984). The revised ASTM Standard on the Unified Classification System. 321 Geotechnical Testing Journal ASTM, 7(4): 216-222.

322 Indian Standard IS2720 (1985). Method of test for soils. Indian Standards Institution, New $323 \quad$ Delhi.

324 Indian Standard IS9259 (1979). Liquid limit apparatus for soils. Indian Standards Institution, $325 \quad$ New Delhi.

326 Jain, L.C. and Patwardhan, N.K. (1960). Physical properties of soils from the Ganges valley. 327 Journal of Scientific and Industrial Research (India), 19A(4): 162-167.

328 Kim, J. B. (1973). A study on the general and one point method of test for liquid limit 329 procedure. Journal of the Korean Society of Agricultural Engineers, 15(4): 3153-3159.

330 Koumoto, T., and Houlsby, G. T. 2001. Theory and practice of the fall cone test. 331 Géotechnique, 51(8): 701-712.

332 Mohan, D. and Goel, R. K. (1958). Rapid methods for determining the liquid limit of soils. $333 \quad$ Journal of Scientific and Industrial Research (India), 17A(12): 498-501.

334 Mohan, D. (1959). Discussion of "The one-point method of determining the value of the 335 liquid limit of a soil”. Géotechnique, 9(3): 143.

336 Nagaraj, T. S., and Jayadeva, M. S. (1981). Re-examination of one-point methods of liquid 337 limit determination. Géotechnique, 31(3): 413-425

338 Newmark, N. M. (1965). Effects of earthquakes on dams and embankments. Géotechnique, $339 \quad$ 15(2): 139-160.

340 Norman, L. E. J. (1959). The one-point method of determining the value of the Liquid Limit 341 of a soil. Géotechnique, 9(1): 1-8.

342 O'Kelly, B. C. (2013). Atterberg Limits \& Remoulded Shear Strength - water content 343 relationships. Geotechnical Testing Journal, 36(6): 939-947. 
344 Olmstead, F. R. and Johnston, C. M. (1954). Rapid methods for determining liquid limits of

345 soils. Highway Research Board Bulletin 95, Washington D. C. (National Research 346 Council Division of Engineering and Industrial Research), pp. 27-35, Discussion, pp. 35$347 \quad 37$.

348 Roje-Bonacci, T. (2004). Liquid limit determination of the high plastic clays by one-point 349 method. Proceedings of the Slovenian Geotechnical Society Conference, 9-11 June 2004.

350 Sridharan, A., Nagaraj, H. B. and Prakash, K. (1999). Determination of the plasticity index 351 from flow index. Geotechnical Testing Journal, 22(2): 169-175.

352 Trevisán, S. J. (1960). Correspondence. Géotechnique, 10(1): 36

353 Vardanega, P. J. and Haigh, S. K. (2014). The undrained strength-liquidity index relationship. 354 Canadian Geotechnical Journal, 51(9): 1073-1086.

355 Warkentin, B. P. (1961) Interpretation of the Upper Plastic Limit of Clays. Nature, 190: 287356288.

357 Waterways Experiment Station (1949). Simplification of the Liquid Limit Test Procedure. 358 Technical Memorandum No. 3-286, U.S. Army Corps of Engineers Waterways $359 \quad$ Experiment Station, Vicksburg, Miss.

360 Wroth, C. P. and Wood, D. M. (1978). The correlation of some index properties with some 361 basic engineering properties of soils. Canadian Geotechnical Journal, 15(2): 137-145.

362 Yilmaz, I. (2009). Swell potential and shear strength estimation of clays. Applied Clay $363 \quad$ Science, 46: 376-384.

364 Yukselen-Aksoy, Y. (2010). Characterization of two natural zeolites for geotechnical and 365 geoenvironmental applications. Applied Clay Science, 50: 130-136.

366 Zentar, R., Abriak, N. E. and Dubois, V. (2009). Effects of salts and organic matter on 367 Atterberg Limits of dredged marine sediments. Applied Clay Science, 42: 391-397. 
369

370

371 Figure 1: International variations in single-point liquid limit formulae

372 Figure 2: Relationship between number of blows for groove closure and specific strength

$373 \quad$ Figure 3: Variation of $\alpha$ with Casagrande Liquid Limit

374 Figure 4: Predicted ratio of plasticity index and flow index

375 Figure 5: Plasticity Index (PI) predicted from Flow Index (FI)

376 Figure 6: Predicted and measured relationships between the Flow Index $(F I)$ and the

$377 \quad$ Liquid Limit $\left(w_{L}\right)$ 
Highlights:

1) Atterberg's liquid limit can be measured rapidly using 1-point methods but these vary worldwide.

2) This paper demonstrates that different methods are a result purely of different equipment, not of soil types

3) The analysis presented shows why a value of $\tan \beta=0.121$ can be used for hard-base equipment and $\tan \beta=0.092$ for soft-base equipment. 
Table 1: Published databases with average $\tan \beta$ values stated

\begin{tabular}{|c|c|c|c|}
\hline Publication & Soil Tested & $\begin{array}{l}\text { Average } \\
\tan \beta \\
\text { value } \\
\text { reported }\end{array}$ & Description of soils tested \\
\hline $\begin{array}{c}\text { Waterways Experiment } \\
\text { Station (1949) }\end{array}$ & 767 US soils & 0.121 & $\begin{array}{c}\text { Recent, Pleistocene, } \\
\text { Tertiary and glacial till. }\end{array}$ \\
\hline $\begin{array}{l}\text { Olmstead and Johnston } \\
\qquad(1954)\end{array}$ & 759 US soils & 0.135 & $15 \%<\mathrm{w}_{\mathrm{L}}<100 \%+$ \\
\hline Eden $(1955,1959)$ & $\begin{array}{l}\text { 484 Canadian } \\
\text { soils }\end{array}$ & 0.100 & - \\
\hline $\begin{array}{c}\text { Mohan and Goel (1958); } \\
\text { Mohan (1959) }\end{array}$ & $\begin{array}{l}250 \text { Indian } \\
\text { soils }\end{array}$ & 0.068 & Black Cotton soil \\
\hline Jain and Patwardhan (1960) & 32 Indian soils & 0.085 & Gangetic alluvium \\
\hline Norman (1959) & $\begin{array}{l}455 \text { British } \\
\text { soils }\end{array}$ & 0.092 & $15 \%<\mathrm{w}_{\mathrm{L}}<170 \%+$ \\
\hline Kim (1973) & $\begin{array}{l}1017 \text { Korean } \\
\text { soils }\end{array}$ & 0.118 & - \\
\hline Roje-Bonacci (2004) & $\begin{array}{l}88 \text { Croatian } \\
\text { soils }\end{array}$ & 0.063 & High-plasticity clays \\
\hline
\end{tabular}


Table 2: Parameters for liquid limit apparatus tested

\begin{tabular}{|c|c|c|c|}
\hline & $\begin{array}{l}\text { ASTM D4318 } \\
(2010)\end{array}$ & BS1377:2 (1990) & $\begin{array}{c}\text { IS9259 (1979) } \\
\text { Indian Institute of Science } \\
\text { (IISc) (Bangalore) }\end{array}$ \\
\hline$a$ & 6.22 & 5.40 & 5.40 \\
\hline$b$ & 21.43 & 173.3 & 374.4 \\
\hline$n$ & 1.893 & 2.226 & 3.510 \\
\hline$\frac{c_{u}}{\rho}$ at liquid limit & 0.932 & 0.376 & 0.432 \\
\hline $\begin{array}{c}\text { Prescribed base } \\
\text { harness }\end{array}$ & 80-90 Shore D & 84-94 IRHD & 86-90 IRHD \\
\hline $\begin{array}{c}\text { Estimated } \\
\text { Young's Modulus }\end{array}$ & $260-446 \mathrm{MPa}$ & $11.5-28 \mathrm{MPa}$ & $13-18.5 \mathrm{MPa}$ \\
\hline $\begin{array}{l}\text { Prescribed } \\
\text { Resilience }\end{array}$ & $77-90 \%$ & $20-35 \%$ & $30-40 \%$ \\
\hline
\end{tabular}


Figure 2
Click here to download Figure: fig2.eps

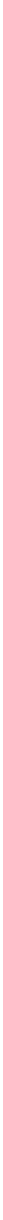


Figure 3

Click here to download Figure: fig3-new.eps

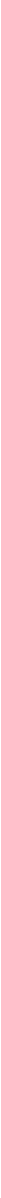


Click here to download Figure: fig5-new.eps
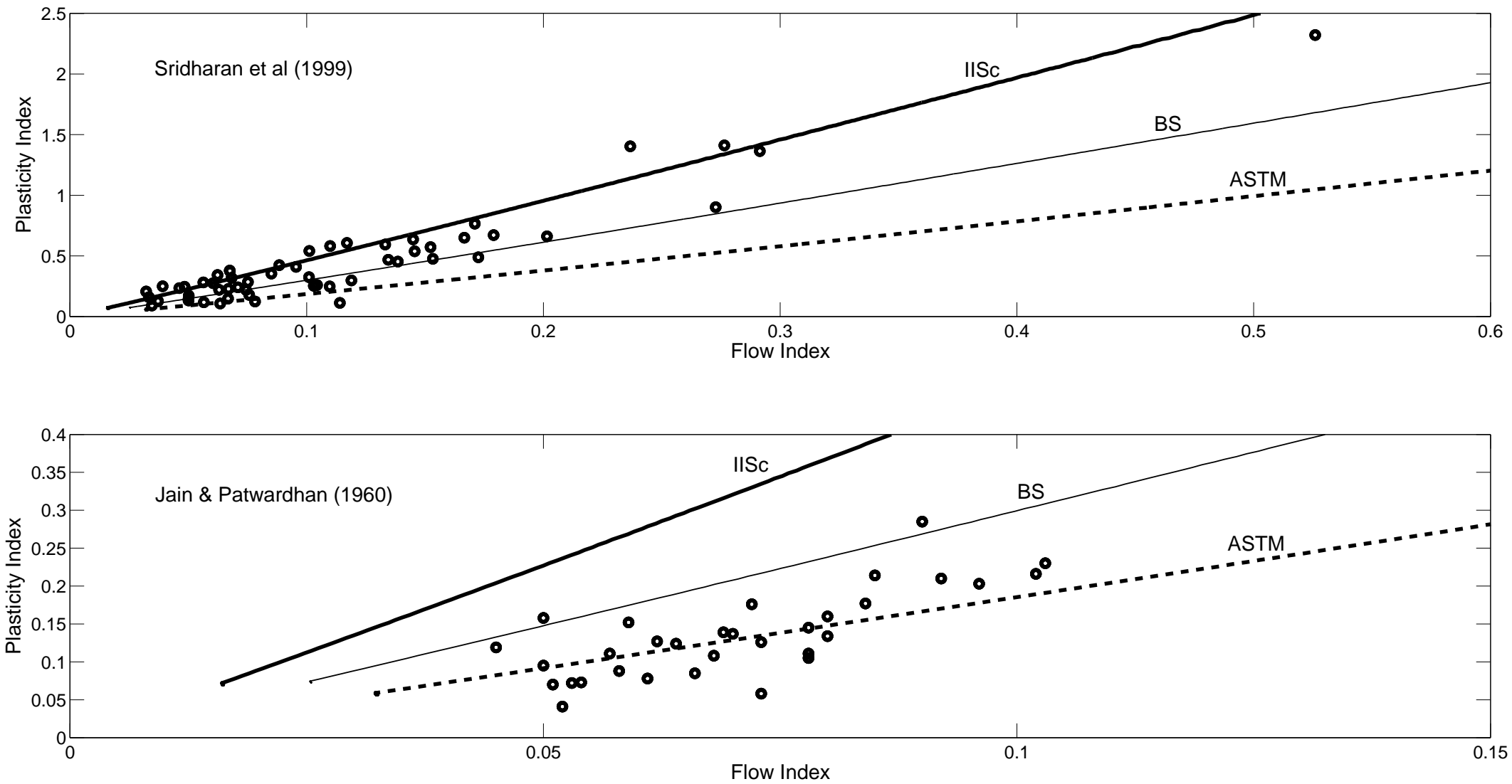
Figure 6
Click here to download Figure: fig6-new.eps

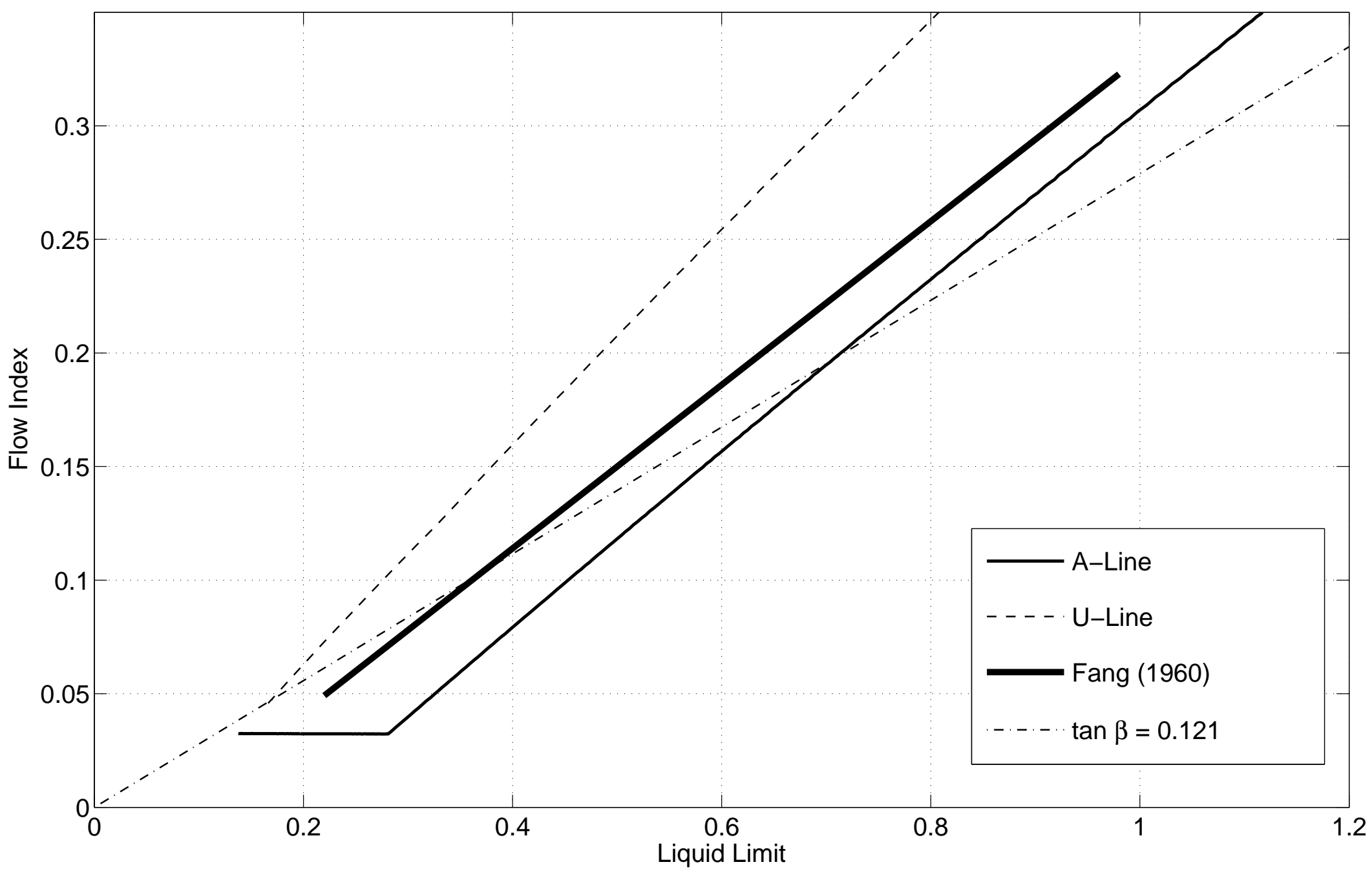

